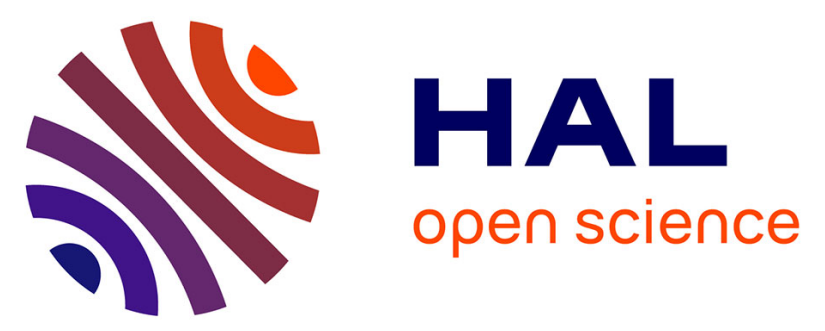

\title{
Abundance weighting for improved vegetation mapping in row crops. Application to vineyard vigour monitoring
}

Saeid Homayouni, Christian Germain, Olivier Lavialle, Gilbert Grenier, Jean-Pascal Goutouly, Cornelis van Leeuwen, Jean-Pierre da Costa

\section{- To cite this version:}

Saeid Homayouni, Christian Germain, Olivier Lavialle, Gilbert Grenier, Jean-Pascal Goutouly, et al.. Abundance weighting for improved vegetation mapping in row crops. Application to vineyard vigour monitoring. Canadian Journal of Remote Sensing, 2008, 34 (Suppl. 2), pp.S228-S239. hal-00345557

\author{
HAL Id: hal-00345557 \\ https://hal.science/hal-00345557
}

Submitted on 9 Dec 2008

HAL is a multi-disciplinary open access archive for the deposit and dissemination of scientific research documents, whether they are published or not. The documents may come from teaching and research institutions in France or abroad, or from public or private research centers.
L'archive ouverte pluridisciplinaire HAL, est destinée au dépôt et à la diffusion de documents scientifiques de niveau recherche, publiés ou non, émanant des établissements d'enseignement et de recherche français ou étrangers, des laboratoires publics ou privés. 
Homayouni et al. Abundance weighting for improved vegetation mapping in row crops. Application to vineyard vigour monitoring.

\title{
Abundance weighting for improved vegetation mapping in row crops. Application to vineyard vigour monitoring.
}

\author{
Research paper
}

S. HOMAYOUNI ${ }^{\dagger}$, C. GERMAIN ${ }^{\dagger}$, O. LAVIALLE ${ }^{\dagger}$, G. GRENIER ${ }^{\dagger}$, J.P. GOUTOULY ${ }^{\ddagger}$, C. VAN LEEUWEN ${ }^{\ddagger}$ and J.P. DA COSTA ${ }^{* \dagger}$

$\dagger$ IMS Laboratory, CNRS UMR 5218, University of Bordeaux, Talence, France. ¥EGFV, INRA UMR 1287, Domaine de la Grande Ferrade, 33883 Villenave d'Ornon, France.

\section{Abstract}

We present a complete framework for vigour mapping in row crops by multispectral remote sensing. The main contribution consists in taking into account vegetation abundance in the computation of vigour indexes. Though developed in a viticulture context, the proposed algorithm is generic enough to be adapted to any row crop, especially in horticulture. It takes advantage of both spectral and spatial features extracted from image data. Spectral information is used at pixel level by an ICA-based algorithm to process vegetation abundance

${ }^{*}$ Corresponding author. Address: IMS, Dpt LAPS, Université Bordeaux 1, 351 Cours de la Libération, 33405 Talence cedex, France. Email: jean-pierre.dacosta@ims-bordeaux.fr. Tél. +33540002634. Fax +33540006644. 
Homayouni et al. Abundance weighting for improved vegetation mapping in row crops. Application to vineyard vigour monitoring.

maps. As for spatial information, deformable models are used to fit a network of rectangles to individual plants. Both spectral and spatial information are then combined to compute abundance-weighted vigour indexes which are assigned to specific plants. Resulting measurements are then used for within block vigour mapping. A validation procedure is carried out on experimental vine plots. It is shown that the use of vegetation abundance by itself or as a weight in the computation of vegetation indexes allows to improve the accuracy of vigour assessment in row crops.

Keywords: Remote sensing, Multispectral data, Precision viticulture, Row crop, Vine, Vegetation index, Spectral unmixing, ICA, Deformable models.

\section{Résumé}

Nous présentons une approche globale pour la cartographie de la vigueur sur des cultures en rangs, basée sur l'étude d'images de télédétection multi spectrales en haute résolution. Notre principale contribution consiste à prendre en compte l'abondance de végétation pour le calcul d'indices de vigueur. Développée dans un contexte viticole, cette approche est transposable à toute culture en rang, notamment en arboriculture. Elle se fonde à la fois sur les propriétés spatiales et spectrales des images. L'information spectrale est exploitée à l'échelle du pixel par un algorithme d'ACI pour produire des cartes d'abondance de végétation. Concernant l'information spatiale, un algorithme de modèles déformables permet d'ajuster un réseau de rectangles aux différentes plantes. Les deux types d'information sont alors combinés pour calculer des indices de vigueur, pondérés par les mesures d'abondance, et d'affecter ces indices à des plants spécifiques de plantes. Les mesures ainsi établies sont finalement utilisées pour la cartographie intra-parcellaire de la vigueur. Une procédure de validation a été mise en place sur une parcelle viticole. Il est montré que la prise en compte de l'abondance directement ou comme pondération dans le calcul d'indices de végétations - permet 
Homayouni et al. Abundance weighting for improved vegetation mapping in row crops. Application to vineyard vigour monitoring.

d'améliorer la mesure de la vigueur sur des cultures en rang.

Mots clés: Télédétection, Données multi spectrales, Viticulture de précision, cultures en rangs, Vigne, Indice de végétation, Séparation spectrale, ACI, Modèles déformables. 
Homayouni et al. Abundance weighting for improved vegetation mapping in row crops. Application to vineyard vigour monitoring.

\section{Introduction}

Estimation, evaluation and monitoring of biomass are key factors for the enhancement of productivity and profitability in agriculture. Vigour, defined as the biomass annually stored per area unit (Champagnol et al. 1984), is an objective measure of biomass. Biomass production concerns various parts of the plant including roots, woods (trunk and shoots), leaves and fruits. Leaves are of particular interest since they are the most visible part of the whole biomass production system, their characteristics being directly affected by the health, stress and diseases of the plants. Quantifying the amount of leaves can thus help in the monitoring of crops during the production season not only in quantity but also in quality. Indeed, in some cases such as viticulture, the highest quality potential is obtained when vine vigour is moderate. Vine vigour is highly variable among vineyard blocks as well as inside the blocks. The reasons for this variability are mainly soil type, soil depth and topography (Bramley et al. 1999). Excessive vigour induces high yield and shaded canopy, resulting in quality losses, whereas very weak vigour leads to yield decrease and financial losses. Reliable vigour monitoring is thus essential to the balanced management of vine production.

Thanks to recent advances in remote sensing, there has been a growing interest in its application to precision agriculture (e.g. Brisco et al. 1998, Tisseyre et al. 1999, Bannari et al. 2002, Hall et al. 2003). In viticulture, multi/hyper spectral airborne/satellite imagery has made possible a flexible mapping of yield, soil and diseases (e.g. Bramley et al. 1999, Lamb 1999, Carothers 2000, Dobrowski et al. 2003, Johnson et al. 2003, Hall et al. 2003, Zarco-Tejada et al. 2005). In particular, various indicators of vigour based on leaf reflectance are accessible by remote sensing imagery, e.g. Rouse et al. (1974), Richardson et al. (1977), Huete (1988). Such indicators, called vegetation indexes (i.e. VI) are computed at the pixel level by combining various bands of the spectral reflectance. They make use of spectral information 
Homayouni et al. Abundance weighting for improved vegetation mapping in row crops. Application to vineyard vigour monitoring.

only without taking into account any spatial information. Simple and fast to compute, they allow the evaluation of vigour while avoiding the direct labour-intensive measurement of biologic features such as the total leaf area. VI maps have been widely used especially for soil covering crops like wheat and corn. In contrast, for perennial woody species conducted in rows such as vines, the presence of a significant amount of bare soil (or cover crop) on remotely sensed images makes biomass quantification by means of VIs less obvious.

Applied to crops such as vines, the precision agriculture concept implies that the plot can not be processed as a whole. Each row, or even each plant, has to be considered separately so that vegetation variability can be described at the plant level. Inter-rows, which often consist of bare soil or grass, should not interfere in the description of the canopy. For such a purpose, very high-resolution images, acquired with either multispectral or hyperspectral sensors, are necessary to attain accurate crop versus non-crop discrimination. Image classification algorithms, e.g. applied to vegetation indexes, can then make use of spatial or/and spectral information to discriminate between crop and non-crop pixels. For instance, in the case of vines, Hall et al. (2003) propose an algorithm ("Vinecrawler") that labels image pixels as vine, if their NDVI values (Rouse et al., 1974) exceed a predefined threshold. They are aggregated into rows which are finally processed as a whole. Semi-automated frameworks have also been applied (Marguerit et al. 2006, Costa Ferreira et al. 2007) to extract vigour information and map it spatially in a row-column system. In these works, the pixels are considered as pure pixels. However, remotely sensed optical images are concerned by spectral mixing i.e. the mix of several contributions in a single pixel. In the particular case of row crops, the pixels can not be classified by basic algorithms into crop or non-crop pixels. The reason is that most pixels result from a mix of crop, inter-row soil, grass and even shadows. Therefore, soft classification techniques or unmixing approaches have to be considered to 
Homayouni et al. Abundance weighting for improved vegetation mapping in row crops. Application to vineyard vigour monitoring.

discriminate between crop and non-crop, or at least to estimate, for each pixel, the abundance of vegetation. Most unmixing approaches are based on supervised or semi-supervised techniques where the spectra of the species or materials are known or are easily available from images (Pacheco et al. 2001, Bannari et al. 2006). Generally such methods deal with non-structured crops at the farm level. Previously, we proposed an unsupervised method for partial unmixing which aimed at evaluating the amount of canopy in each pixel (Homayouni et al. 2006). It was applied to viticulture, at the plot level.

In this paper, a non supervised framework is proposed to transform high resolution multispectral images of row crops into vegetation vigour maps. Its main point is to take advantage of both spectral and spatial features to produce improved vigour indexes that take the row layout into consideration. Spectral information is used at pixel level to compute abundance coefficients which are used as weights in the computation of vegetation and leaf area indexes. Spatial information is used to bring back spectral measurements to specific row and plant positions.

Section 2 is dedicated to the description of our framework. In section 2.1, we recall the main principles of the row detection algorithm presented in (Bobillet et al. 2003). It aims at an accurate positioning of rows and individual vines for further spatialization of spectral measurements. In section 2.2, we address the problem of spectral mixing. A method is proposed for the semi-automated production of abundance maps based on independent component analysis. Then, in section 2.3 a geometric procedure is proposed to combine spatial information about rows and spectral information from abundance maps and vegetation indexes. It results in plant by plant vigour estimations. In section 3, the whole procedure is applied and validated on multispectral images of vineyards. Plant scale measurements are used to produce vigour maps by interpolation. They are finally correlated to ground 
Homayouni et al. Abundance weighting for improved vegetation mapping in row crops. Application to vineyard vigour monitoring.

measurements for global validation of the framework.

\section{A new framework for vigour analysis}

\subsection{The row detection algorithm}

Most computer vision methods for detecting crop rows are implemented in real-time systems for automatic guidance of agricultural implements (e.g. Keicher and Seufert 2000, Hague and Tillet 2001). Images are taken by on-board cameras and show only a small number of rows. The Hough transform is often used to recover the linear structures (Marchant 1996, Keicher et al. 2000). Usually, the very high resolution of the considered images and the small number of rows lead to sufficiently accurate results. When lower computational time is required, tracking algorithms based on Kalman filtering (Hague et al., 2001) or linear regression approaches (Søgaard et al., 2003) are also implemented.

Unlike the real-time context, computational time is not a critical issue for accurate location of rows in crop monitoring by remote sensing. On the other hand, row position and row angle estimations have to be very precise, due to the image size and to the length of the rows. The specific arrangement of individual crops suggests the use of the Hough transform. However, previous attempts, not reported in this paper, have shown that the Hough transform is not adapted to locate vine rows. The large number of linear structures and the presence of undesirable alignments make the row detection difficult.

In order to retrieve the rows with high accuracy, we have chosen an algorithm based on active contour models, i.e. snakes (Kass et al. 1988), previously described in (Bobillet et al. 2003). This algorithm implements an active contour network which aims at fitting a line to each row through a global convergence process. Prior segmentation of the parcel is needed so that peripheral vegetation, buildings, roads etc. do not interfere in the row detection process. 
Homayouni et al. Abundance weighting for improved vegetation mapping in row crops. Application to vineyard vigour monitoring.

Figure 1 shows an example of segmentation obtained on a vine parcel using the algorithm described in (Da Costa et al., 2007). This prior segmentation step can be manual or automatic.

Figure 1. Left: typical high-resolution remote sensing image of a vineyard in the visible spectrum. Right:

$$
\text { segmented version. }
$$

Both the segmentation and the row detection algorithms operate on greyscale images. The multispectral image under consideration has thus to be transformed into a grey scale image which discriminates the crop rows from their background. This is done easily by computing any vegetation index, e.g. NDVI (Rouse et al., 1974) using the red and infra-red spectral bands.

In spite of their apparent regularity, row crop images may show some particularities that make the detection process difficult. Rough measurements of average row spacing and orientation are not sufficient for a fine detection. Indeed, row spacing and orientation are only approximately constant over the field. For instance, perspective distortion effects can explain a gradual variation of row orientation across the image.

The active contour model is designed according both to ideal row properties and to the particularities that may occur. Rows are considered as roughly parallel segments. The model chosen in (Bobillet et al. 2003) is a network of quasi-parallel segments.

The geometry of the segment network is controlled by the minimization of a pre-defined energy $E$ :

$$
E=\mu E_{\text {int }}+(1-\mu) E_{\text {ext }}
$$

where $E_{\text {int }}$ and $E_{\text {ext }}$ are respectively the internal and the external energies. $E_{\text {int }}$ reflects the internal constraints that the snake undergoes. The external energy $E_{\text {ext }}$ takes into account the effect of the image. It enables the attraction of the snake towards the desired state. $\mu$ is a 
Homayouni et al. Abundance weighting for improved vegetation mapping in row crops. Application to vineyard vigour monitoring.

weighting parameter. Formulations of $E_{\text {int }}$ and $E_{\text {ext }}$ and details of implementation can be found in (Bobillet et al. 2003). Figure 2 shows an example of row detection results obtained on the parcel of figure 1 using this method. The lines appear to fit almost perfectly the central axis of each vine row overcoming the irregularity of foliage and the absence of some vine plants.

Figure 2. Left: Row detection result. Middle: detail \#1. Right: detail \#2.

The network of lines obtained by the active contour algorithm allows to go beyond the simple detection of crop rows. Indeed, as many perennial crops, vine is usually planted regularly i.e. with constant distance between rows and between vine stocks. Such information can be used to place a regular network of rectangles along the detected rows (see Figure 3). The length of the rectangles corresponds to the distance between two consecutive stocks. Their width corresponds to the trimming width. These features depend on the agricultural practices used in the region or even in the agricultural estate. They can be provided to the algorithm by the end-user.

Figure 3. Left: Row detection result. Middle: detail \#1. Right: detail \#2.

Once the exact positions and occupation areas of individual plants are determined, the quantification of crop vigour can be carried out at the scale of the plant by taking spectral information into account. This process is described below.

\subsection{Estimation of vegetation abundance maps by partial spectral unmixing}

\subsubsection{Modelling the remotely sensed data}

A VNIR (Visible and Near Infrared) remote sensing system is an electro-optical system designed to observe the radiations reflected by ground objects at wavelengths generally comprised between 0.4 and $2.5 \mu \mathrm{m}$. In such a system, the outputs, i.e. the image pixel data or digital numbers (DNs), are assumed to be linear combinations of the inputs, i.e. the spectral 
Homayouni et al. Abundance weighting for improved vegetation mapping in row crops. Application to vineyard vigour monitoring.

reflectances or radiances (Schowengerdt 2006). This assumption, usually valid at a macroscopic level, implies that various effects (e.g. topographic variations, atmospheric effects, specular reflectance, etc.) are negligible. Several physical models have been proposed to represent such observation systems and to analyze their effects on observed spectra (Schowengerdt 2006). Let $D N(x, y, \lambda)$ be the digital number recorded by the sensor at pixel $(x, y)$ and wavelength $\lambda$. It can be expressed as follows:

$$
D N(x, y, \lambda)=f\left(R(x, y, \lambda), P_{i}\right)
$$

where $R$ is the spectral reflectance of the ground sampling unit corresponding to $(x, y)$ at wavelength $\lambda$. The $P_{i}$ are the physical parameters involved in the whole remote sensing system: the atmosphere, the scene geometry and the sensor features. If a linear model is considered, the $D N$ s are linearly related to the reflectance or at-sensor radiance. A multispectral image can thus be expressed in matrix form by:

$$
X_{n \times m}=R_{n \times p} \times A_{p \times m}+N_{n \times m}
$$

$R_{n \times p}$ contains the reflectance (signature or end-member) of $p$ materials in $n$ spectral bands. $A_{p \times m}$ is a combination matrix: in the case of remote sensing applications, it contains the abundances $a_{i j}$ of the $p$ materials on each of the $m$ pixels. $N_{n \times m}$ is a residual matrix. Finally, $X_{n \times m}$ contains the recorded pixel data (DNs). If the elements of $A_{p \times m}$ satisfy the constraints of additivity $\left(\forall j, \sum_{i=1}^{p} a_{i j}=1\right)$ and positivity $\left(\forall i, j, a_{i j} \geq 0\right)$, this model is similar to the Linear Spectral Random Mixture model proposed in (Chang 2003).

In the contexts of detection and classification of spectral classes, $A_{p \times m}$ has to be estimated. This estimation can be viewed as an inverse problem for which Blind Sources Separation techniques (BSS), including Independent Component Analysis (ICA), are appropriate 
Homayouni et al. Abundance weighting for improved vegetation mapping in row crops. Application to vineyard vigour monitoring.

solutions.

\subsubsection{Independent Component Analysis}

ICA brings a solution for BSS under the assumption of linear mixing i.e. when the multivariate observations are assumed to be unknown linear mixtures of some unknown latent variables, the independent components (i.e. sources or factors):

$$
X=M \times S+N
$$

$X$ is the observation matrix and $S$ the sources. $M$ is called the mixing matrix and $N$ represents additive noise. The aim of ICA is to estimate $S$ using an inverse model:

$$
\hat{S}=W \times X
$$

where $W$, the separating matrix is an estimate of $M^{-1}$. In this regard, ICA is similar to Principal Component Analysis (PCA). However, while PCA minimizes the correlation between estimated components, ICA aims at the independence of the components. The estimation of independent components is possible under the following assumptions (Hyvarinen and Oja, 2000):

- the mixture is actually linear,

- the sources are mutually independent,

- the number of Gaussian sources is at most one,

- the number of sources is less than the number of observations.

ICA algorithms are based on the optimization of a criterion quantifying the independence of components. This criterion is usually based on higher order statistical moments. The optimization of this function will lead to maximize the independence of components, i.e. to minimize their mutual information. In this regard, several algorithms for ICA are available in 
Homayouni et al. Abundance weighting for improved vegetation mapping in row crops. Application to vineyard vigour monitoring.

literature including Jade (Cardoso and Souloumiac, 1993) which is based on the joint probability function, FastICA (Hyvarinen and Oja, 2000) relying on the minimization of contrast functions (typically kurtosis), or the method proposed by Robila and Varshney (2002) which minimizes mutual information.

Regarding multispectral images, ICA is generally used according to two strategies. The first one, (Bayliss et al. 1998, Kosaka and Kosugi 2003) considers as sources the spectral signatures of the various classes (the end-members). In contrast, in the second one, the sources are class abundances (e.g. Robila and Varshney 2002, Shah 2004). Abundance values range continuously from low values to high values corresponding respectively to the absence and to the presence of an individual class within a specific pixel.

In the present work, we chose the second strategy. For vigour analysis in row crops, the source of interest is the one related to crop abundance, e.g. vine abundance in the case of viticulture. Other sources are related to soil, other types of vegetation, etc. The assumption of mutual independence of the sources entails that the vine class abundance does not depend on other possible sources as for instance bare soil or grass. Although this assumption does not hold - abundances sum to 1 - ICA usually provides relevant sources from which meaningful information about vegetation abundance can be extracted. Concerning non-Gaussianity, the useful source, i.e. the one related to vegetation, is usually non-Gaussian. Indeed, in practice, the crop abundance source is coarsely bi-modal as it is composed of rather crop-like pixels with high crop abundance values and rather non crop-like pixels with low crop abundance values. Other possible sources depend on the image content. They may be related to non-crop vegetation species (e.g. grass, trees), to ground targets or to soil variations. Gaussian-like sources usually correspond to residual noise and bear no information about vegetation abundance. 
Homayouni et al. Abundance weighting for improved vegetation mapping in row crops. Application to vineyard vigour monitoring.

\subsubsection{Component selection}

In general, ICA implementations are unsupervised and do not allow any component ranking. Neither the rank nor the energy of the components makes any sense in ICA. Consequently, even if the ICA algorithm provides a "crop-like" source, the latter must be retrieved among all the sources. Although this task seems straightforward if done manually, making it automatic is not so easy. The selection of meaningful components is often carried out using statistical criteria (e.g. higher order moments, entropy). However, it seems difficult in our case to select the crop component by using the statistical characteristics of its distribution. For this reason, we tackled the problem of component selection from a biological point of view. Indeed, in the agricultural context of vigour mapping, we can benefit from additional information provided by vegetation indices. If the available spectral data comprise sufficient information to compute a vegetation index $I$, then the crop component $V$ can easily be selected by choosing, between all extracted sources $\hat{S}_{i}$, the one which is the most correlated to $I$ :

$$
V=\underset{\hat{S}_{1}, \ldots, \hat{S}_{p}}{\arg \max }\left|\operatorname{Corr}\left(\hat{S}_{i}, I\right)\right| .
$$

Though efficient in most of cases, this criterion may not work in the presence of grass between the rows as it could result in an independent component by itself. However, such a case has not occurred in practice since grass, when present, is usually associated with vine, composing together a vegetation component. Indeed, spectral information extracted from multi-spectral data, is not sufficient to separate vegetation species such as grass and vine. Such discrimination requires enhanced spectral information. The presence of grass will not be addressed here.

\subsubsection{Component normalization}

As mentioned previously, there are constraints imposed by the spectral mixing model that 
Homayouni et al. Abundance weighting for improved vegetation mapping in row crops. Application to vineyard vigour monitoring.

ICA can not account for. The signs and the magnitudes of the components can not be directly determined and the additivity property mentioned earlier is not verified. The components can not be directly considered as abundances. In particular, the vine component identified by maximizing its correlation to the vegetation index is not necessarily positive nor bounded to $[0,1]$

Some authors propose to take the constraints of the mixing model into account in the source separation algorithm itself (Chang 2003, Nascimento and Dias 2003), the outputs of which can be directly considered as abundances. In our case, the crop abundance is obtained $a$ posteriori using a soft classification scheme. The classification is performed by a Fuzzy CMeans technique (FCM) (Bezdek et al. 1984). Compared to classical clustering techniques (e.g. K-means), FCM is more robust to outliers and has the advantage of providing for each pixel a membership degree to each class. The only requirement is to set the number of clusters a priori. Regarding the vine component, the values of the pixels relate to the presence or the absence of vine. In the best case, the histogram of this component may be bi-modal (vine and non-vine pixels). Applied to this vine component, the FCM technique is thus expected to provide a measure of the abundance of vine i.e. an estimation of the percentage of the pixel area covered by vine. From now on, this vine abundance will be denoted $A$. Figure 4 gives a schematic illustration of vine abundance estimation.

Figure 4. From multispectral images to the vine abundance map

\subsection{Precise vigour estimation along rows}

The use of the active contour model described above makes it possible to take measurements along crop rows and to assign the measured feature to a precise locus on the row. The feature to be measured will depend on the type of crop, on the agricultural practices, and on the type 
Homayouni et al. Abundance weighting for improved vegetation mapping in row crops. Application to vineyard vigour monitoring.

of information needed by the end-user. The width of the canopy, though an intuitive feature, does not always bear meaningful information about crop vigour since, in horticulture, the canopy is sometimes controlled by lateral trimming. Such an agricultural practice is quite common in viticulture, for instance in the region of Bordeaux. In such cases, vegetation vigour must be assessed by other means, for example by measuring a vegetation index (VI) related to the biological status of the plant or by estimating vegetation thickness through a leaf area index (LAI). Below, we describe the method we chose to compute these indexes and to average them at the scale of the plant, combining both spatial information about plant layout and spectral information about crop abundance.

\subsubsection{About vegetation indexes}

A Vegetation Index (VI) is a measure without dimension which is usually a non linear combination of spectral bands of multispectral data. The formulations of VIs are based on the reflection properties of leaves (Gates et al. 1965). Advantages are their simplicity of implementation and their low computational cost. However, their use is limited by some important drawbacks: they are non linear and saturated for highly vigorous vegetation, and are hindered by atmospheric and soil effects. There are two main categories of VIs: ratio based and orthogonal based (see Table 1). Ratio based VIs have long been studied in agricultural and environmental applications. The various formulations attempt to reduce the sensitivity to exterior conditions (Zarco-Tejada et al. 2005). They can also be used to discriminate vegetation from its environment or as measures of plant vigour (Rouse et al. 1974, Hall et al. 2003). Orthogonal indexes, such as PVI (Richardson et al. 1977) or SAVI (Huete 1988), take the spectral reflection of soil into account but need prior calibration. They are particularly relevant in the case of leaf area measurements.

Table 1. Some ratio-based and orthogonal-based vegetation indexes. R and IR respectively denote the reflectance 
Homayouni et al. Abundance weighting for improved vegetation mapping in row crops. Application to vineyard vigour monitoring.

magnitudes in the Red and Infra-Red channels. L, a and b are constants used to compute orthogonal indexes.

\begin{tabular}{lll}
\hline & Formula & References \\
\hline Difference Vegetation Index & DVI $=$ IR $-\mathrm{R}$ & Tucker (1979) \\
Simple Ratio Index & $\mathrm{SRI}=\mathrm{IR} / \mathrm{R}$ & Pearson \& Miller (1972) \\
Normalized Difference Vegetation Index & $\mathrm{NDVI}=(\mathrm{IR}-\mathrm{R}) /(\mathrm{IR}+\mathrm{R})$ & Rouse et al. (1974) \\
Infrared Percentage Vegetation Index & $\mathrm{IPVI}=\mathrm{IR} /(\mathrm{IR}+\mathrm{R})$ & Crippen (1990) \\
\hline Perpendicular Vegetation Index & $\mathrm{PVI}=(\mathrm{IR}-\mathrm{a} \cdot \mathrm{R}-\mathrm{b}) / \sqrt{\left(1+\mathrm{a}^{2}\right)}$ & Richardson et al. (1977) \\
Soil Adjusted ratio Vegetation Index 1 & $\mathrm{SAVI1}=(1+\mathrm{L}) .(\mathrm{IR}-\mathrm{R}) /(\mathrm{IR}+\mathrm{R}+\mathrm{L})$ & Huete (1988) \\
Soil Adjusted ratio Vegetation Index 2 & $\mathrm{SAVI}=\mathrm{IR} /(\mathrm{R}+\mathrm{b} / \mathrm{a})$ & Major et al. (1990) \\
Transformed Soil-Adjusted Vegetation Index & $\mathrm{TSAVI}=\mathrm{a} *(\mathrm{IR}-\mathrm{a} * \mathrm{R}-\mathrm{b}) /(\mathrm{a} * \mathrm{IR}+\mathrm{R}-\mathrm{a} * \mathrm{~b})$ & Baret et al. (1989) \\
\hline
\end{tabular}

\subsubsection{An estimated leaf area index.}

The Leaf Area Index, i.e. LAI, defined as half the green leaf area per area unit (Welles et al. 1991), is known to be a realistic indicator of vigour. As its direct measurement potentially affects the health of the leaves, it can not be carried out over the whole parcel. Pruning weight or PW, i.e. the weight of the shoots pruned after harvest, is another vigour related feature. Its measurement is delayed in winter and can thus be exhaustive. However, both LAI and PW are labour intensive and time consuming and cannot be used as a routine for crop monitoring.

Instead, indirect estimation of LAI is possible, as described in (Ross 1981). The estimation eLAI is obtained as follows:

$$
e L A I=-\ln (P) \cdot \cos (\alpha) / G(\alpha),
$$

where $P$ is the probability that a beam of radiation with incidence angle $\alpha$ passes through the canopy, supposed uniform and composed of leaves with random angular and spatial distributions. $G(\alpha)$ is the mean projection coefficient of unit foliage area on a plane perpendicular to $\alpha$.

To estimate $e L A I$ from spectral data, $\cos (\alpha) / G(\alpha)$ can be determined at 0.5 for plants which 
Homayouni et al. Abundance weighting for improved vegetation mapping in row crops. Application to vineyard vigour monitoring.

have randomly distributed leaf angles such as agricultural crops (Norman 1979). The incidence angle $\alpha$ corresponds to the sensor viewing zenith angle. Airborne optical remote sensors are usually pointed at a view angle of 0 (nadir looking). $P$ represents the gap (nonvegetation) fraction, which is determined by spectral unmixing as follows:

$P=1-A$, where $A$ is the vine abundance. $e L A I$ is then derived according to the following formula:

$$
e L A I=-2 \ln (1-A)
$$

This leaf area index, together with the abundance-weighted vegetation indexes, will now be evaluated and compared within the experimental framework described hereafter.

\subsubsection{Enhancing vegetation and leaf area indexes by abundance weighting}

Any vigour indicator, i.e. vegetation or leaf area index, is all the more interesting as it can be computed at the scale of the plant and assigned to a specific plant position. A straightforward way to do this is to make use of the rectangle networks extracted through the active contour algorithm (see section 2.1). The vigour indicator is averaged over the pixels comprised in the rectangle and assigned to the centre of the rectangle.

In practice, for vegetation indexes, the presence of other classes inside the rectangles (i.e. soil, shadows, etc.), together with the mixing phenomenon, hinder the correct assessment of vigour. However, the effect of these non-vegetation pixels is easily reduced by weighting the vegetation index by the vine abundance:

$$
\overline{V I}_{k}=\sum_{i \in k^{t h} \text { rectangle }} a_{i} V I_{i} / \sum_{i \in k^{t h} \text { rectangle }} a_{i}
$$

where $\overline{V I}_{k}$ is the vigour associated with the $k^{\text {th }}$ stock, $V I_{i}$ is the vegetation index value on pixel $i$ and $a_{i}$ is the abundance of vegetation on pixel $i$. Finally, the vine vigour values $\overline{V I}_{k}$ 
Homayouni et al. Abundance weighting for improved vegetation mapping in row crops. Application to vineyard vigour monitoring.

are assigned to the rectangle centroids so as to constitute a regular grid of pointwise values for mapping purposes.

Concerning eLAI, a simple average computed over the pixels comprised in the rectangles is sufficient, making the assessment of vigour even more straightforward.

Fig. 4. Left: segment network obtained through the row detection algorithm. Middle: rectangle network corresponding to the vine stocks. Right: the rectangle centroids.

\section{Experimental evaluation}

The measurements carried out using the methods described above are point scale information. Herein, they can be used directly when information about individual plants is needed. On the contrary, they are not adapted for a global representation of the parcel vigour variability. In order to make such data easy to interpret and to use by experts and even by farmers, maps are necessary. This is done by interpolation of the plant-scale measurements.

After a brief presentation of the vineyard parcel and of the data we used for experimental validation, we will show some vigour maps obtained from plant-scale vigour measurements. These maps will help in the qualitative comparison between the various vigour indexes produced by our global framework and the ground truth data collected on the parcel. Finally, statistical correlation results between ground truth and image-based measurements will provide a quantitative evaluation of the global framework.

\subsection{Images and ground truth data}

The evaluation is carried out on vineyards of the Bordeaux area. The image analysis framework developed in this work, is applied to multi spectral aerial silver photographs acquired in July 2006 and digitized at a resolution of 4800 dpi. These images are composed of green, red and infrared spectral bands. The camera was taken on board a light airplane. Flying 
Homayouni et al. Abundance weighting for improved vegetation mapping in row crops. Application to vineyard vigour monitoring.

altitude was low to allow very high spatial resolution i.e. 7-10 cm/pixel. An example of such data is shown in figure 5 , in the form of a false colour image.

Figure 5. False colour image of an experimental plot with radiometric/geometric targets.

Besides remotely sensed images, ground truth data were collected for validation. These data were collected in an experimental parcel under a specific protocol. The parcel consisted of 19 rows, each composed of 82 vine plants, with no grass between rows. A network of experimental plots was designed. Each plot was $0.5 \mathrm{~m}$ wide, $3 \mathrm{~m}$ long and includes three vine plants. The whole network was composed of 96 plots, i.e. a total of 288 vine plants on which Pruning Weight measurements were carried out in November 2006.

Radiometric and geometric targets, which appear as white spots in the image, are ground control points meant for the geo-referencing of images. The precision of the geo-referencing is related to the accuracy of the GPS, typically $5 \mathrm{~m}$ or $1 \mathrm{~m}$ at best with post-treatment, which is sufficient for standard vigour cartography. In contrast, the geo-positioning of ground measurements and image data requires a much better accuracy since both image resolution (less than $10 \mathrm{~cm} /$ pixel) and plant size $(0.5 \mathrm{~m} \times 1 \mathrm{~m})$ are smaller than the accuracy of standard GPS. In our case, we chose not to use GPS-based positioning but rather to take advantage of the strict regularity of plant layout. Indeed, the exact geometry of the parcel is known, including the number, positions and lengths of the rows and the distances of the plants from the beginning of the row. It is thus possible to perform geo-referencing of ground measurements and image data, within a local coordinate system with no reference to terrestrial coordinates. As the beginning of the rows can be determined on images with a resolution of about 2 to 3 pixels because of foliage irregularity, geo-positioning accuracy falls down to 20 or $30 \mathrm{~cm}$, out-performing standard GPS resolution. 
Homayouni et al. Abundance weighting for improved vegetation mapping in row crops. Application to vineyard vigour monitoring.

\subsection{Vegetation vigour maps}

Various vigour-related indexes were extracted. Both ratio-based and orthogonal vegetation indexes (section 1.2) were computed. The eLAI, estimated Leaf Area Index, was deduced from abundance maps. Three indexes, NDVI, PVI and eLAI are illustrated in figure 6.

These indexes were combined with geometric information to produce plant-scale vigour measurements according to the geometric framework described in section 2.3. These measurements were inserted into a GIS (ArcGIS) and manipulated as vector data for mapping. Within block vigour maps were created by inverse distance interpolation. The three corresponding vigour maps are shown in figure 6.

Figure 6 . The three vigour-related indexes and corresponding vigour maps obtained by inverse distance interpolation. From top to bottom: NDVI, PVI and eLAI. Low vigour is represented in white, high vigour in dark green.

Though we will not comment further the interest of such maps for agricultural monitoring, it is worthwhile mentioning some properties of these maps. First, they allow enhancing the variability of vigour, difficult to observe in the original index images. Secondly, the global structures of the three maps are similar with particularly strong resemblance between PVI and eLAI.

Figure 7. Scatter plots. Left: between NDVI and eLAI. Right: between PVI and eLAI.

Figure 7 shows the scatter plots between the two vegetation indexes, NDVI and PVI, and the leaf area index eLAI. The data are the measurements carried out on the experimental plots described above. Less than $10 \%$ outliers were excluded which corresponded to missing canopy (missing plants or deviated canopy). While the relation between NDVI and eLAI is rather loose, the linearity of the correlation between PVI and eLAI is clear, with a high correlation coefficient. 
Homayouni et al. Abundance weighting for improved vegetation mapping in row crops. Application to vineyard vigour monitoring.

\subsection{Correlation between vigour maps and ground truth data}

An experimental validation of the framework was carried out by statistical analysis. eLAI measurements and ground truth pruning weights were compared, at the scale of the experimental plots described in section 3.1. The scatter plot between the two statistical series is shown in Figure 8.

Figure 8. Scatter plot between eLAI and Pruning Weight, with the linear regression trend.

The relation is more or less linear. After omission of the outliers corresponding to missing plants, the determination coefficient is $R^{2}=0.48$, i.e. a coefficient of correlation $R=0.69$, which is reasonably good $\left(p \ll 10^{-3}\right.$ with sample size $\left.N=90\right)$. Remaining variability can be explained in part by inaccurate positioning of field data and probably by soil irregularity, in spite of abundance weighting. Luminosity variations due to reflection effects and shades can also be incriminated.

Similar analyses were conducted on vegetation indexes including ratio-based and orthogonal vegetation indexes. Table 2 groups the correlation coefficients obtained in two cases, depending on whether the vegetation indexes are uniformly weighted or weighted by the vine abundance-values. The results show that the use of abundance values as weights allows enhancing the correlation between image-based and ground measurements. In other words, the abundance values seem to reduce the effect of non-vegetation pixels and thus to refine vegetation indexes. Besides, it can be noted that DVI, a very simple vegetation index, appears to outperform other indexes after abundance weighting, even orthogonal ones, in spite of the relative complexity of their computation. Finally, it appears that eLAI, directly computed from the abundance values, is as correlated to pruning weights as the best vegetation indexes.

Table 2. Correlations between Vegetation Indexes and Pruning Weight. 
Homayouni et al. Abundance weighting for improved vegetation mapping in row crops. Application to vineyard vigour monitoring.

\begin{tabular}{llll}
\hline & & Uniform weighting & Abundance-based weighting \\
\hline DVI & Difference Vegetation Index & 0.56 & 0.68 \\
SRI & Simple Ratio Index & 0.60 & 0.63 \\
NDVI & Normalized Difference Vegetation Index & 0.55 & 0.63 \\
IPVI & Infrared Percentage Vegetation Index & 0.55 & 0.63 \\
\hline PVI & Perpendicular Vegetation Index & 0.55 & 0.67 \\
SAVI1 & Soil Adjusted ratio Vegetation Index 1 & 0.55 & 0.63 \\
SAVI2 & Soil Adjusted ratio Vegetation Index 2 & 0.57 & 0.58 \\
TSAVI & Transformed Soil-Adjusted Vegetation Index & 0.56 & 0.63 \\
\hline
\end{tabular}

\section{Conclusions and prospects}

A semi-automated framework is proposed to transform high resolution multispectral images of row crops into vegetation vigour maps. Though developed in a viticulture context, this method is generic enough to be adapted to any row crop, especially in arboriculture. It takes advantage of both spectral and spatial features extracted from image data. Spectral information is used at pixel level to process partial unmixing and to compute enhanced vegetation and leaf area indexes. Spatial information is used to bring back spectral measurement to specific row and plant positions. Resulting measurements are finally used for within block vigour mapping or plant scale characterization of crops.

A validation procedure was carried out on experimental vine plots where ground pruning weight measurements were available. Various image-based vigour indicators were computed and showed comparable performances. For all indicators, enhanced results were obtained using vegetation abundance as a weight for vigour computation. Besides, the estimated Leaf Area Index, eLAI, directly computed from the abundance values, proved to be as correlated to pruning weights as the best vegetation indexes, including orthogonal vegetation indexes. This result is noteworthy, considering that such indexes are quite difficult to compute, for they require to calibrate the image according to local soil characteristics. This makes of eLAI, 
Homayouni et al. Abundance weighting for improved vegetation mapping in row crops. Application to vineyard vigour monitoring.

computed using the unsupervised algorithm proposed in this paper, an interesting alternative to standard indexes, especially for large commercial applications where calibration is not systematic.

Finally, this work showed very promising results. The degree of correlation between ground data and image-based measurements confirms, in the case of row crops, the potential of multispectral imagery for canopy characterization. Furthermore, the significant improvement obtained using abundance information suggests to take into account abundance based weighting to improve the accuracy of vigour assessment.

Future works will concern the refinement of the approach. Particularly, we intend to test and improve the whole framework on enhanced image data. Actually, the poor spectral resolution of the multispectral images used in this work certainly hinders the quality of vegetation index estimation, thus penalizing vigour estimation. With such spectral resolution, discrimination between different kinds of vegetation, e.g. grass and vine, is not possible either, which makes the present approach of limited use when inter-rows are covered by grass. The use of hyperspectral data, with both numerous and narrow spectral channels, should surely open up new horizons in future. Modern hyperspectral sensors, beyond being both technically and economically competitive, are also much less bulky than previous heavy acquisition systems thus allowing easy and cheap airborne acquisitions. Not only enhanced vigour characterization and mapping but also species discrimination should then be attainable, provided that sufficient spatial resolution is available.

\section{Acknowledgments}

This work was carried out with the financial support of the FEDER Interreg IIIB program, within the PIMHAI project. We are grateful to the experimental domain of Couhins, for 
Homayouni et al. Abundance weighting for improved vegetation mapping in row crops. Application to vineyard vigour monitoring.

allowing image acquisitions.

\section{References}

Bannari, A., Pacheco, A., Staenz, K., McNairn, H., and Omari, K. 2006. Estimating and mapping crop residues cover on agricultural lands using hyperspectral and IKONOS data. Remote Sensing of Environment, Vol. 104, pp. 447-459.

Bannari, A., Staenz K., and McNairn, H. 2002. Synergy among GIS, GPS and Hyperspectral Remote Sensing in Precision Farming. In Proc. of the Int. Symp. on Geospatial Theory, Processing and Applications, July, Ottawa, Ontario.

Baret, F., Guyot, G., and Major, D.J. 1989. TSAVI: a vegetation index which minimizes soil brightness effects on LAI and APAR estimation. In Proceedings of the 12th Canadian Symposium on Remote Sensing and IGARSS'89, Vancouver, Canada, Vol. 3, pp. 1355-1358.

Bayliss, J., Gualtieri, J., and Cromp, R. 1998. Analyzing Hyperspectral Data with Independent Component Analysis. In Proceedings of the SPIE, Vol. 3240, pp. 133-143.

Bezdek, J., Ehrlich, R., and Full, W. 1984. FCM: The Fuzzy CMeans Clustering Algorithm. Computers and Geoscience, Vol. 10, pp. 191-203.

Bobillet W., Da Costa J.P., Germain C., Lavialle O., and Grenier G. 2003. Row detection in high resolution remote sensing images of vine fields. In Proceedings of ECPA 2003, Berlin, Germany, pp. 81-88.

Bramley, R., and Proffitt, A. 1999. Managing variability in viticultural production. Grapegrower and Winemaker, pp. 11-16.

Brisco, B., Brown, R., Hirose, T., and McNairn, H. and Staenz, K. 1998. Precision agriculture and the role of remote sensing: a review. Canadian Journal of Remote Sensing, Vol. 24, pp. 
Homayouni et al. Abundance weighting for improved vegetation mapping in row crops. Application to vineyard vigour monitoring.

$315-327$.

Cardoso, J.F., and Souloumiac, A. 1993. Blind Beamforming for non-Gaussian Signals. Proceedings of the IEEE, Vol. 140, No. 6, pp. 362-370.

Carothers, J. 2000. Imagery technology meets vineyard management. Practical Winery and Vineyard, Vol. 21, No. 1, pp. 54-62.

Champagnol, F. 1984. Eléments de physiologie de la vigne et de viticulture générale, In French.

Chang, C.-I. 2003. Hyperspectral Imaging: Techniques for spectral detection and classification, Kluwer Academic/Plenum Publishers, New York, USA.

Costa Ferreira, A.M., Da Costa, J.P., Germain, C., Grenier, G., Homayouni, S., Marguerit, E., Roby, J.P., and Van Leeuwen, C. 2007. Transformation of high resolution aerial images in vine vigour maps at intra-block scale by semi automatic image processing. In Proceedings of the $15^{\text {th }}$ International Symposium of the GESCO, Juin, Porec, Croatia, pp. 1372-1381.

Crippen, R. E., 1990. Calculating the vegetation index faster. Remote Sensing of Environment, Vol. 34, pp. 71-73.

Da Costa, J., Michelet, F., Germain, C., Lavialle, O., and Grenier, G. 2007. Delineation of Vine Parcels by Segmentation of High Resolution Remote Sensed Images. Precision Agriculture, Vol. 8, pp. 95-110.

Da Costa, J., Germain, C., Lavialle, O., and Grenier, G. 2008. A New Framework for the Segmentation and the Characterization of Row Crops. Application to Vineyard Monitoring. Computers and Electronics in Agriculture, under revision.

Dobrowski, S., Ustin, S., and Wolpert, J. 2003. Grapewine dormant pruning weight prediction 
Homayouni et al. Abundance weighting for improved vegetation mapping in row crops. Application to vineyard vigour monitoring.

using remotely sensed data. Australian Journal of Grape and Wine Research, pp. 177-182.

Elvidge, C. 1990. Visible and near Infrared reflectence characteristics of dry plant materials. Int. J. Remote Sensing, Vol. 11, pp. 1775-1795.

Gates, D.M., Keegan, H.J., Schleter, V.R., and Weidner, V.R. 1965. Spectral properties of plants. Applied Optics, Vol. 4, pp. 11-20.

Hague, T., and Tillet, N.D. 2001. A bandpass filter-based approach to crop row location and tracking. Mechatronics, Vol. 11, pp. 1-12.

Hall, A., Louis, J., and Lamb, D. 2003. Characterising and mapping vineyard canopy using high spatial-resolution aerial multispectral images. Computers and Geosciences, Vol. 29, pp. $813-822$.

Homayouni, S., Da Costa, J.P., Germain, Ch., Lavialle, O., and Grenier, G. 2006. Partial unmixing of multi or hyperspectral images using ICA and Fuzzy Clustering techniques. Application to vegetation mapping on vineyards. In Proceedings of AECRIS 2006, Preston, United Kingdom, pp. $115-122$.

Huete, A.R. 1988. A soil-Adjusted Vegetation Index (SAVI), Remote sensing of environment, Vol. 25, pp. 295-309.

Hyvarinen, A., and Oja, E. 2000. Independent Component Analysis: algorithms and applications. Neural Networks, Vol. 13, pp. 411-430.

Johnson, L., Roczen, D., Youkhana, S., Nemani, R., and Bosch, D. 2003. Mapping vineyard leaf area with multispectral satellite imagery. Computers and Electronics in Agriculture, Vol. 38, No. 1, 37-48.

Kass, M., Witkin, A., and Terzopoulos, D. 1988. Snakes: Active Contour Models, International 
Homayouni et al. Abundance weighting for improved vegetation mapping in row crops. Application to vineyard vigour monitoring.

Journal of Computer Vision, Vol. 4, 321-331.

Keicher, R., and Seufert, H. 2000. Automatic guidance for agricultural vehicles in Europe. Computers and Electronics in Agriculture, Vol. 38, No. 1-2, 169-194.

Kosaka, N., and Kosugi, Y. 2003. ICA aided linear spectral mixture analysis of agricultural remote sensing images. In: Proceedings of the 4th International Symposium on Independent Component Analysis and Blind Signal Separation, pp. 221-226.

Lamb, D. 1999. Monitoring vineyard variability from the air. Australian Viticulture, Vol. 3, No. 6, pp. 22-23.

Major, D.J., Baret, F. and, Guyot, G. 1990. A ratio vegetation index adjusted for soil brightness. International Journal of Remote Sensing, Vol. 11, pp. 727-740.

Marchant, J.A. 1996. Tracking of row structure in three crops using image analysis. Computer and Electronics in Agriculture, Vol. 15, pp. 161-179.

Marguerit, E., Costa-Ferreira, A.M., Azais, C., Roby, J.P., Goutouly, J.P., Germain, C., Homayouni, S., and Van Leeuwen, C. 2006. La télédetection à haute résolution pour spatialiser les variations intra-parcellaires de la vigueur de la vigne, in French. In Proceedings of the sixth International Terroir Congress, Bordeaux-Montpellier, pp. 286-291.

Nascimento, J., and Dias, J. 2003. Does independent component analysis play a role in unmixing hyperspectral data? In Pattern Recognition and Image Analysis (Lecture Notes in Computer Science). Edited by F. Perales, A. Campilho, N. Sanfeliu. Springer-Verlag Heidelberg, pp. 616-625.

Norman, J. 1979. Modelling the Complete Crop Canopy. In Modification of the Aerial Environment of Plants. American Society of Agricultural Engineers, St. Joseph, Michigan.

Ollat, N., Fermaud, M., Tandonnet, J., and Neveux, M. 1998. Evaluation of an indirect method 
Homayouni et al. Abundance weighting for improved vegetation mapping in row crops. Application to vineyard vigour monitoring.

for leaf area index determination in the vineyard: Combined effects of cultivar, year and training system. Vitis, Vol. 37, pp. 73-78.

Pacheco A., A. Bannari, A., Deguise, J.-C., McNairn, H., and Staenz, K. 2001. Contribution of Hyperspectral Remote Sensing for LAI Estimation in Precision Farming. In Proceedings of the 23rd Canadian Symposium on Remote Sensing, Sainte-Foy (Québec), pp. 281-287.

Pearson, R.L. and Miller, L.D., 1972. Remote mapping of standing crop biomass for estimation of the productivity of the short-grass prairie, Pawnee National Grasslands, Colorado, Proceedings of the Eighth International Symposium on Remote Sensing of Environment, ERIM International, pp. 1357-1381.

Richardson, A.J., and Wiegand, C.L. 1977. Distinguishing vegetation from soil background information. Photogrammetric Engineering \& Remote Sensing, Vol. 43, pp. 1541-1552.

Robila ,S.A., and Varshney, P.K. 2002. A Fast Source Separation Algorithm for Hyperspectral Imagery. In Proceedings of IEEE Geoscience and Remote Sensing Symposium, IGARSS '02, Vol. 6, pp. $3516-3518$.

Ross, J. 1981. The Radiation Regime and Architecture of Plant Stands. Series “Tasks on Vegetation Science”, Vol. 3, Junk: The Hague (distributed by Springer).

Rouse, J., Haas, J., Deering, R., Schell, J., and Harlan, J. 1974. Monitoring the vernal advancement and retrogradation (green wave effect) of natural vegetation. In III final report, NASA/GSFC, Greenbelt, MD.

Schowengerdt, R.A. 2006. Remote Sensing: Models and Methods for Image Processing, Third Edition, Elsevier Academic Press, Inc.

Shah, C.A. 2004. Hyperspectral Classification using ICA based Mixture Model. In Advanced Image Processing Techniques for Remotely Sensed Hyperspectral Data, Springer, Berlin, pp. 217-236. 
Homayouni et al. Abundance weighting for improved vegetation mapping in row crops. Application to vineyard vigour monitoring.

Søgaard, H.T., and Olsen, H.J. 2003. Determination of crop rows by image analysis without segmentation. Computers and Electronics in Agriculture, Vol. 38, pp. 141-158.

Tisseyre, B., Ardoin, N., and Sevila, F. 1999. Precision viticulture: precise location and vigour mapping aspects. In Proceedings of the ECPA, Odense, Denmark, pp. 319-330.

Tregoat, O., Ollat, N., Grenier, G., and Van Leeuwen, C. 2001. Etude comparative de la précision et de la rapidité de mise en oeuvre de différentes méthodes d'estimation de la surface foliaire de la vigne. Journal International des Sciences de la Vigne et du Vin, Vol. 35, pp. 31-39.

Tucker, C. J., 1979. Red and Photographic Infrared Linear Combinations for Monitoring Vegetation. Remote Sensing of Environment, Vol. 8, pp. 127-150.

Van Leeuwen, C., Goutouly, J.P., Costa-Ferreira, A.M., Azais, C., Marguerit, E., Roby, J.P., Chone, X., Germain C., Homayouni, S., and Gaudillère, J.P. 2006. Intra-block variations of vine status in time and space. In Proceedings of the Sixth International Terroir Congress, Bordeaux-Montpellier, pp. 64-69.

Welles, J., and Norman, J. 1991. Instrument for indirect measurement of canopy architecture. Agronomy Journal, Vol. 83, pp. 818-825.

Wildman, W., Nagaoka, R., and Lider, L. 1983. Monitoring spread of grape phylloxera by color infrared aerial photography and ground investigation. American Journal on Enology and Viticulture, Vol. 34, pp. 83-94.

Zarco-Tejada, P.J., Berjon, A., Lopez-Lozano, R., Miller, J.R., Martin, P., Cachorro, V., Gonzalez, M.R., and De Frutos, A. 2005. Assessing vineyard condition with hyperspectral indices: Leaf and canopy reflectance simulation in a row structured discontinuous canopy. Remote Sensing of Environment, Vol. 99, pp. 271-287. 
Homayouni et al. Abundance weighting for improved vegetation mapping in row crops. Application to vineyard vigour monitoring.
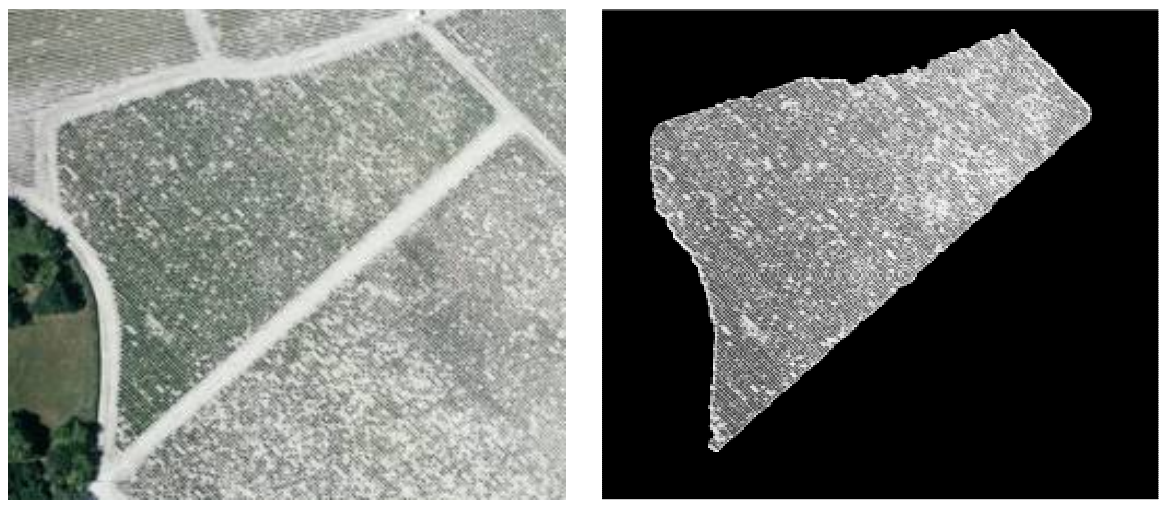

Figure 1. Left: Typical high-resolution remote sensing image of a vineyard in the visible spectrum. Right: segmented version.
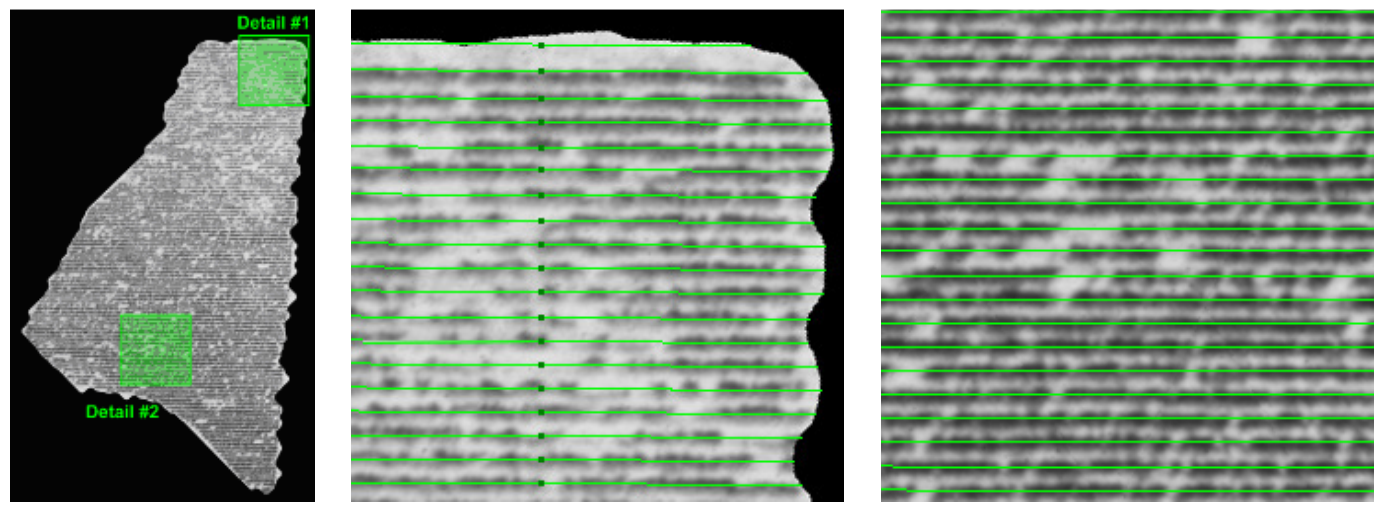

Figure 2. Left: Row detection result. Middle: detail \#1. Right: detail \#2. 
Homayouni et al. Abundance weighting for improved vegetation mapping in row crops.

Application to vineyard vigour monitoring.
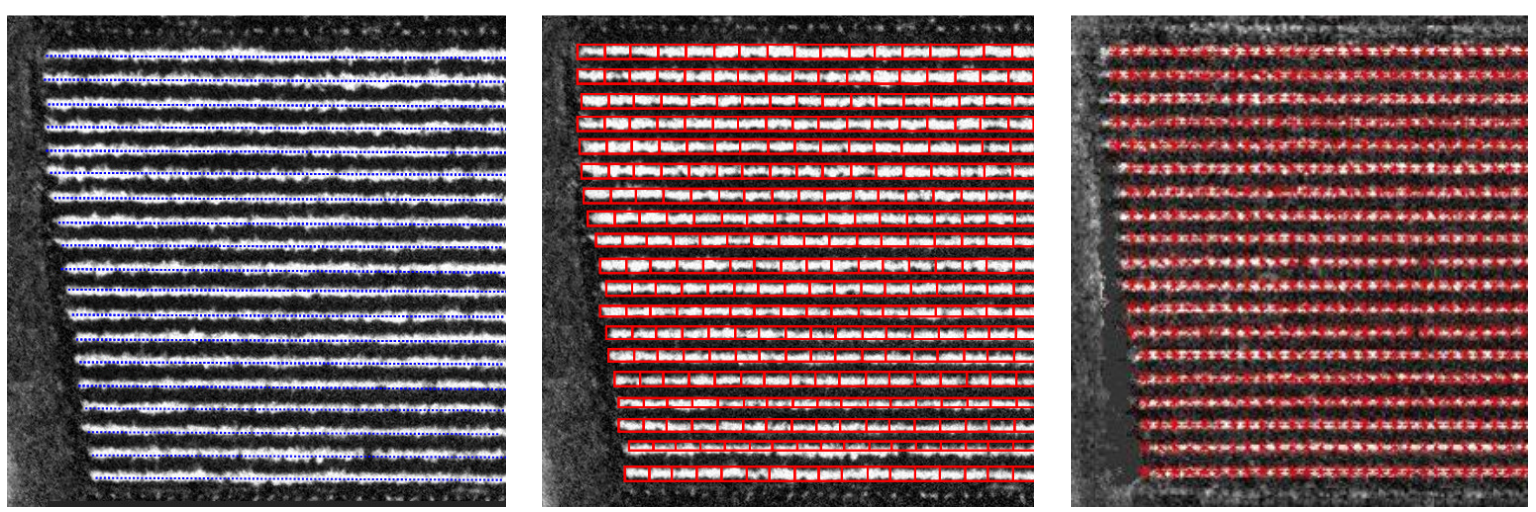

Figure 3. Positioning individual plants along crop rows. Left: segment network obtained through the row detection algorithm on an experimental plot. Middle: rectangle network corresponding to the vine stocks. Right: the rectangle centroids.

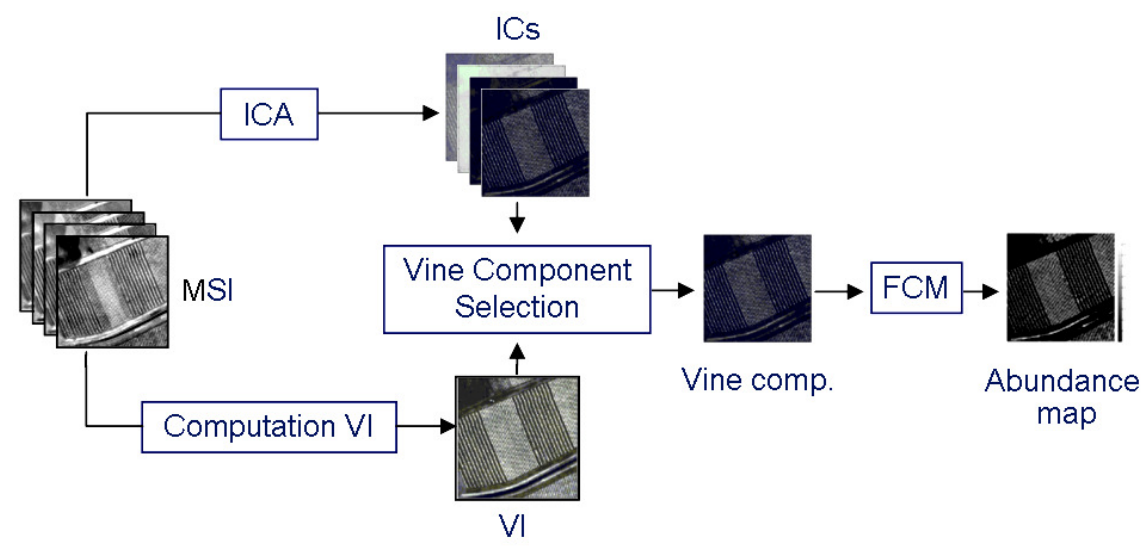

Figure 4. From multispectral images to the vine abundance map 
Homayouni et al. Abundance weighting for improved vegetation mapping in row crops. Application to vineyard vigour monitoring.

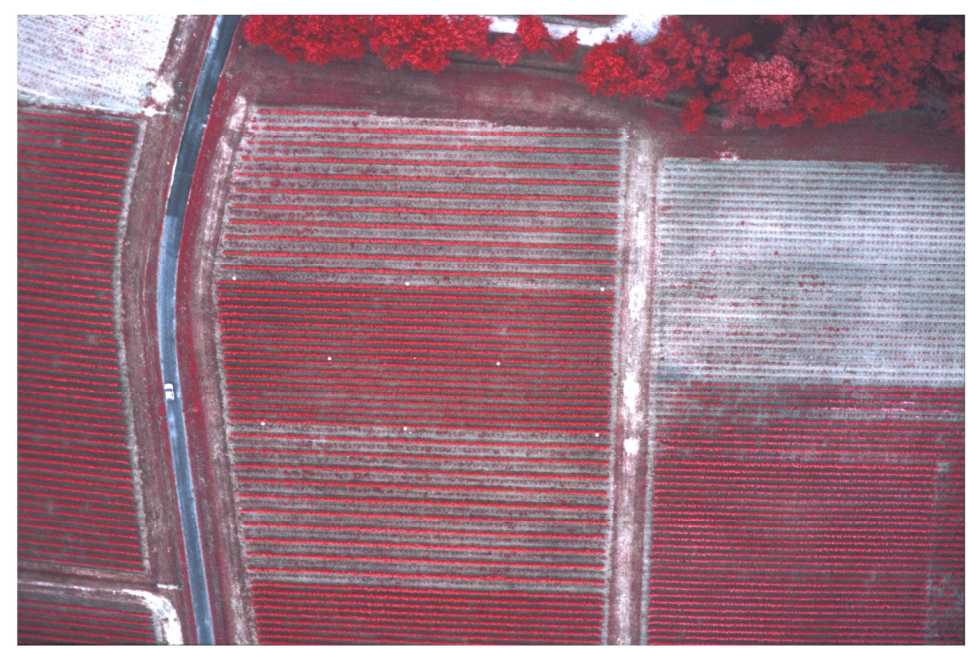

Figure 5. False colour image of an experimental plot with radiometric/geometric targets. 
Homayouni et al. Abundance weighting for improved vegetation mapping in row crops.

Application to vineyard vigour monitoring.
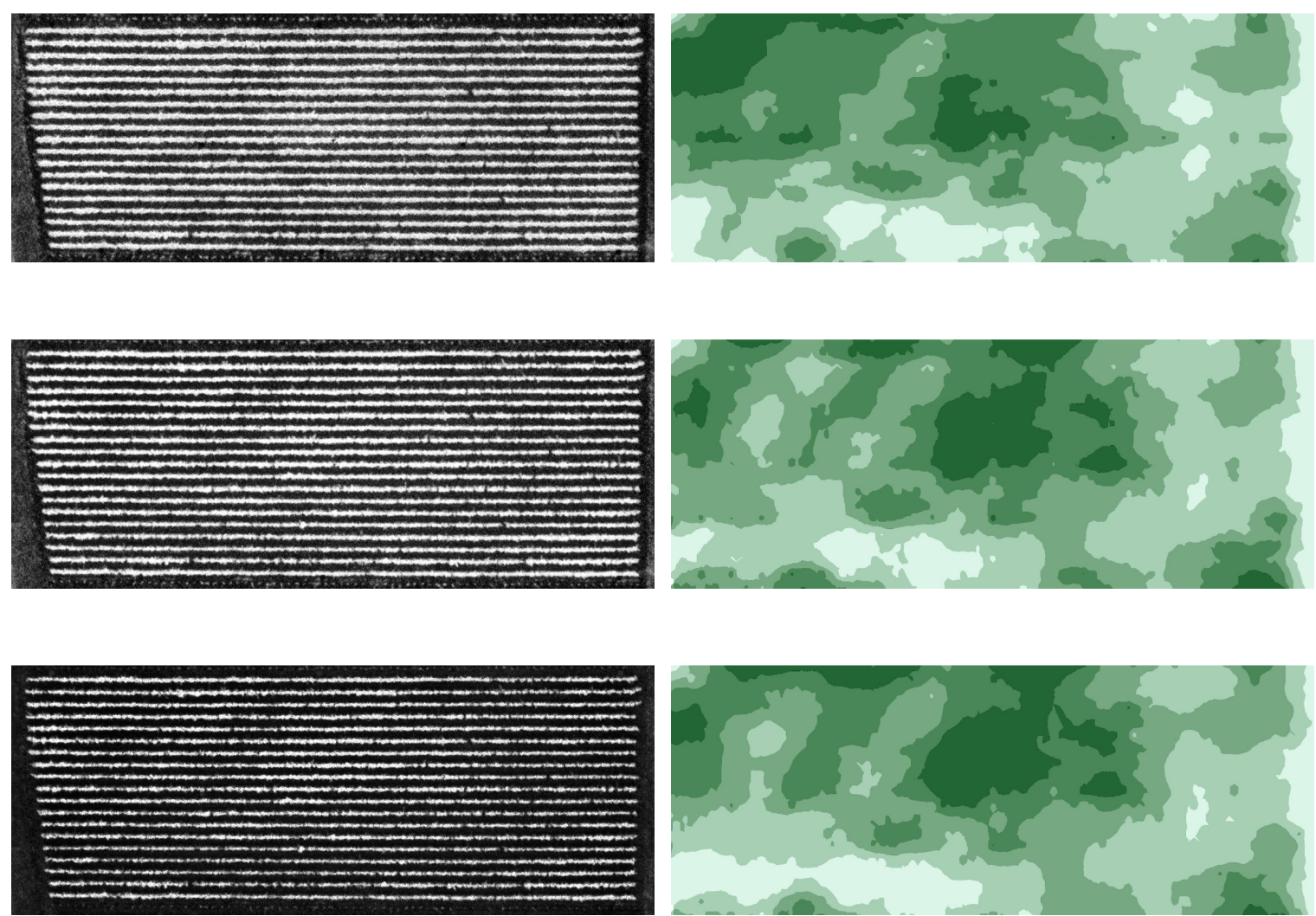

Figure 6 . The three vigour-related indexes and corresponding vigour maps obtained by inverse distance interpolation. From top to bottom: NDVI, PVI and eLAI. Low vigour is represented in white, high vigour in dark green.
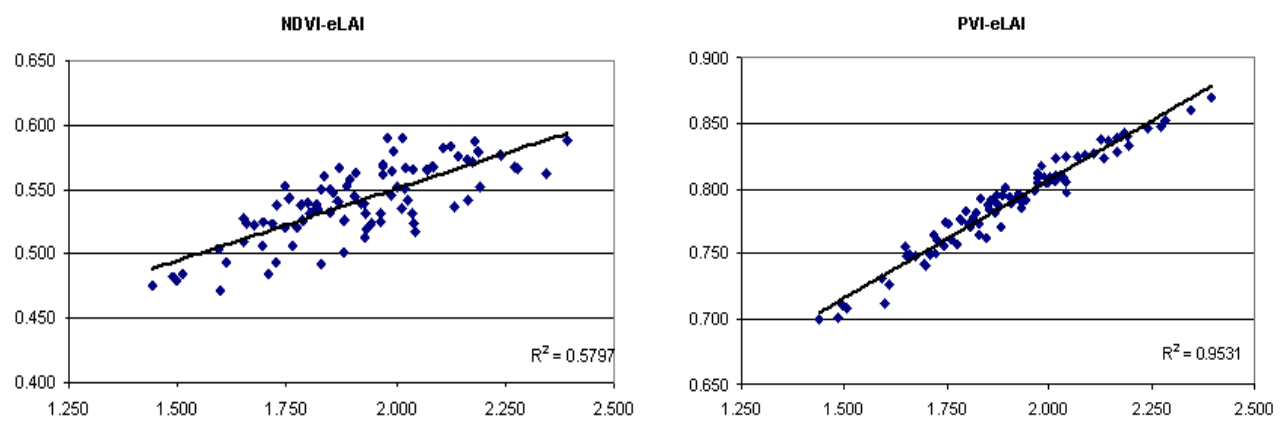

Figure 7. Scatter plots. Left: between NDVI and eLAI. Right: between PVI and eLAI. 
Homayouni et al. Abundance weighting for improved vegetation mapping in row crops. Application to vineyard vigour monitoring.

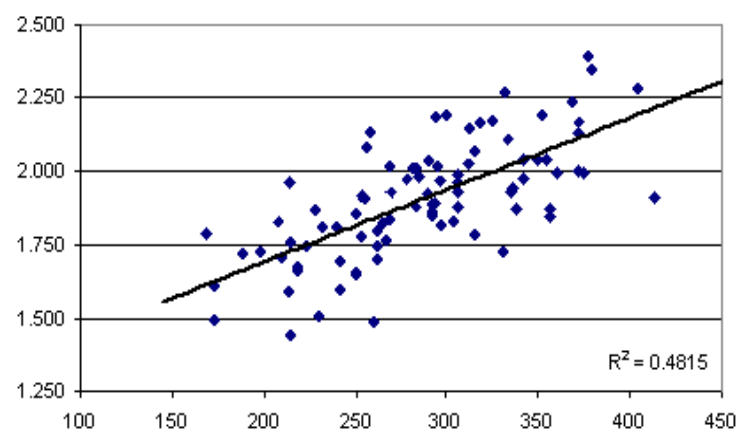

Figure 8. Scatter plot between eLAI and Pruning Weight, with the linear regression trend. 